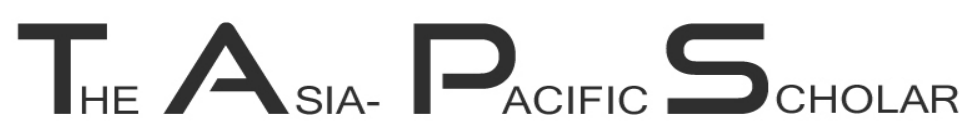 \\ MEDICAL AND HEALTH PROFESSIONS EDUCATION
}

\section{Teaching the generalisable skills of cultural competency: A new educational intervention in New Zealand}

\author{
Katharine D. Thomas ${ }^{1} \&$ Susie Schofield ${ }^{2}$ \\ ${ }^{1}$ Department of Family Medicine, Sackler Faculty of Medicine, Tel Aviv University, Israel; ${ }^{2}$ Centre for Medical Education, \\ University of Dundee, United Kingdom
}

\begin{abstract}
Context: In the twentieth century "cultural" courses in medical education focused on imparting knowledge about ethnic and racial minorities. A new consensus has developed that emphasises a broader definition of culture: education should promote generalisable skills enabling effective interactions with all patients in our culturally complex world. In New Zealand, cultural competency is frequently taught within courses on the indigenous Māori people. This study evaluated whether a generalisable cultural competency intervention was acceptable and effective in this setting.

Methods: A generalisable cultural competency workshop was run for 17 general practitioners. A self-assessment questionnaire was completed by attendees and by a control group of 19 GPs. Participants provided feedback during the seminar and through standardised evaluation forms. Four medical education professionals were interviewed to explore their views on cultural competency education. The interviews were transcribed and thematically analysed.

Results: The questionnaires showed a non-significant, post-seminar increase in total cultural competency score by the seminar participants as compared with the control group $(p=.33)$. Feedback was positive, with all respondents considering the seminar relevant to their needs. The interviewees supported generalisable cultural competency but lacked consensus around whether it should stand-alone or be embedded in ethnically-focused education.

Conclusions: This pilot study shows that participants found generalisable cultural competency education acceptable and that they perceived an improvement in their skills. Medical educators disputed the role of generalisable cultural competency. Further research is needed into how it can be utilised in New Zealand.
\end{abstract}

Keywords: $\quad$ Medical Education, Cultural Competency, Physicians

Practice Highlights

- Generalisable cultural competency aims to enable successful interactions with all patients.

- It was acceptable to learners more familiar with ethnically focused cultural education.

- There was a lack of consensus as to whether generalisable cultural competency should be taught as a stand-alone subject.

\section{INTRODUCTION}

Towards the end of the last century, it began to be accepted that culture and health are interrelated (Helman, 1984; Kleinman, Eisenberg, \& Good, 1978). As a result, many medical institutions began including what can be broadly described as "cultural competency" in the curriculum (Beach et al., 2005). The ethnic focus of many of these early courses has been criticised for potentially promoting stereotypes and ethnocentricism, the belief that the predominant culture is superior (Kai,
Bridgewater, \& Spencer, 2001; Núñez, 2000). Many experts suggest that cultural competency education should focus on more generalisable skills such as selfreflection and negotiation to enable physicians to interact effectively with all patients in culturally, socially and linguistically diverse settings (Gregg, \& Saha, 2006; Sorensen et al., 2017). "Physicians need a practical set of tools and skills that will enable them to provide quality care to patients everywhere, from anywhere, with 
whatever differences in background may exist" (Betancourt, 2006, p. 499).

New Zealand has a unique history in terms of its indigenous Māori people as well as in cultural competency education. Legislation passed in 2000 and 2003 required that the principles of the Treaty of Waitangi, an agreement signed in 1840 between the British Crown and Māori leaders, be incorporated into health care policy, education and practice, and that health care practitioners be "culturally competent". These requirements have led to cultural competency guidelines and programmes that focus on Māori language, customs and health inequalities (Jones et al., 2010; Smith, \& Jansen, 2006; The Royal New Zealand College of General Practitioners [RNZGP], 2007) and to partnerships with Māori professionals in producing cultural competency programming (Medical Council of New Zealand [MCNZ], 2017). Whilst additional educational programmes have been introduced which focus on ethnic immigrants to New Zealand, particularly Pacific Islanders (Camplin-Welch, 2007), at the time of writing no generalisable cultural competency programmes exist in New Zealand.

An educational intervention was designed by the authors that focused on the generalisable skills of cultural competency. As a pilot project for future interventions, it also articulates the process and complexities of implementing such programs for medical professionals. This study aimed to evaluate both its effectiveness and its acceptability for participants, and it considered the acceptability of generalisable cultural competency from a broader perspective of its situation in the New Zealand context where cultural competency education is predominantly ethnically and Māori focused.

\section{METHODS}

\section{A. Educational Intervention}

The first author (KT) devised and facilitated a small group, active learning workshop that combined established principles of medical education with a focus on generalisable cultural competency. Prior to it being run, the researcher discussed its content with the Primary Health Organisation (PHO) Director of Māori Health. It was also evaluated and endorsed by the New Zealand Royal College of General Practitioners as appropriate for continuing professional development accreditation.

A small group, informal setting was created to allow what may be sensitive or divisive issues to be discussed and to give all members of the group the opportunity to participate. The three and a half hour workshop included viewing a video of a meeting between a doctor and a patient from ethnically different backgrounds; an exercise to promote self-reflection on the meaning of culture and identity; a twenty minute lecture which included definitions of culture and cultural competency, a review of ethnic diversity in New Zealand and a case study highlighting the importance of generalisable cultural competency in a clinical context; smaller groups of three or four participants reviewed cases studies and allied exercises taken from the website of Cross Cultural Health Care - Case Studies (Horky, 2009). This was followed by a role play in which participants played both the doctor and the patient in several cross-cultural scenarios.

In order to maintain the small group structure, the number of participants per session was limited and it was run on two separate days in identical format.

\section{B. Cultural Competency Questionnaire Development}

The Cultural Competency Assessment Tool (CCAT; Kutob, Senf, \& Harris Jr, 2009), a self-assessment questionnaire, was adapted for this study. The CCAT questionnaire was chosen because it was designed specifically for family physicians and its validity and reliability had been adequately demonstrated.

Several questions relating to particular ethnic or racial groups were removed or modified and a new question was inserted regarding patients' socioeconomic situation. Additionally, the focus on diabetes management in the original questionnaire was reduced. The questionnaire was re-validated by gaining input from several general practitioners (GPs), followed by piloting with 19 GPs not in the study.

Reliability was re-evaluated using Cronbach alpha analysis ( $\alpha=0.82$; Canty, \& Ripley, 2012; Falissard, 2012). No changes were made to the questionnaire after piloting. The revalidated version contains 22 Likert questions with a maximum possible score of 88 (refer to Appendix A).

Co-variance analysis of the questionnaire results for the workshop and control groups was used to assess whether the differences in scores on the questionnaires carried out before and after the educational intervention were of statistical significance. Only those who completed the questionnaire twice were included. A second analysis with "last observation carried forward" considered the effects of the lower rate of return of the second round of questionnaires. 


\section{Workshop Participants and Control Group}

All 230 GPs and GP registrars whose clinics are affiliated to a PHO in the Wellington area were offered the opportunity to attend a cultural competency workshop as part of their Continuing Professional Development (CPD) programme. The same group of 230 GPs was invited alternatively to be part of the control group who would not attend the workshop but would fill in the cultural competency questionnaire, nineteen responded. Seventeen GPs attended the workshop, nine at the first seminar and eight at the second.

\section{Workshop Evaluation}

Effectiveness and acceptability of the workshop were evaluated in several ways: 1) the cultural competency self-assessment questionnaire was used to evaluate the workshop's effect on participants' perceived cultural competency. It was completed by workshop participants prior to and one month after the workshop. One month was chosen as a time scale during which participants could have time to reflect but would not have been affected by other interventions; 2) workshop participants provided verbal feedback to the researcher directly at the end of the teaching session; 3) several participants emailed feedback to the researcher or wrote it on their questionnaires; and 4) at the end of the workshop participants completed a standard CPD evaluation form provided by the PHO.

Data were coded on the self-assessment questionnaires and entered for computer analysis using EPI-INFO version 3.5.3 software. For statistical analysis, proportions were compared using the chi-square statistic. Significance was set at $P<.05$ and means of continuous variables were compared using the Student's $t$-test.

\section{E. Interviews}

Whilst workshop participants contributed to the assessment of the acceptability of generalisable cultural competency for individuals, they also raised questions as to its acceptability in the broader context of New Zealand medical education.

During the second workshop one participant, Dr KR who at the time was Tumuaki Māori/Māori Director, of the Royal New Zealand College of General Practitioners provided feedback on elements of the session and their relationship to Māori culture and health education. The author was struck by the strength of her comments and felt that a greater comprehension of her views could contribute to the consideration of the place and acceptability of generalisable cultural competency within New Zealand's medical education system. KR agreed to be interviewed for this study. A semi-structured interview was carried out with questions considering the seminar's acceptability, the role of cultural competency and ethnically specific education in New Zealand as well as the acceptability of generalisable cultural competency in this setting. The one and a half hour interview was audio recorded and transcribed by KT.

The richness of the data led to three other medical educators being invited to be interviewed in order to further explore the role of generalisable cultural competency in the New Zealand context. Two (Dr BG and Dr SM were Pakeha [New Zealanders of European origin]) GPs, who had attended the seminars and are active in student and GP trainee education. They both work in urban practices with patients from many different ethnic backgrounds. The other (MM) was Māori, and Director of Māori Health for the PHO, who had discussed the workshop with the lead author prior to its being conducted. She has a background of many years working in health care as a nursing and mental health clinical leader as well as a number of roles relating specifically to Māori service provision and health. The interviewees were chosen as they were both familiar with the workshop and with health care provision in New Zealand as well as being involved in New Zealand medical education. All interviewees have agreed to be identified.

The structure and content of the three subsequent interviews were based on the interview with $\mathrm{KR}$, and are shown in Appendix B.

\section{RESULTS}

\section{A. Cultural Competency Questionnaires}

Sixteen of the seventeen (94\%) GPs who attended the workshops completed questionnaires prior to the sessions. Fifteen (88\%) completed the second round of questionnaires one month later. Of the control group, 19 completed the questionnaire at the same time as the intervention group, and 10 (53\%) completed the questionnaire a second time, one month later.

Table 1 summarises the demographic details of the workshop and control groups. The total questionnaire scores increased amongst the group of doctors who attended the seminars from a mean of 62.7 prior to the seminar to 64.3 one month later. In the control group, the total questionnaire score went down in the second round of questionnaires from a mean of 62.9 to 61.9 (Table 2). 


\begin{tabular}{lcc}
\hline & $\begin{array}{c}\text { Seminar Group } \\
\text { no. (\% of total) }\end{array}$ & $\begin{array}{c}\text { Control Group } \\
\text { no. (\% of total) }\end{array}$ \\
\hline Mean age (years) & 52 & 47 \\
Completed vocational training in New Zealand & $10(62.5)$ & $14(73.7)$ \\
Completed vocational training elsewhere & $5(31.5)$ & $4(21.5)$ \\
Gender, Female & $11(68.8)$ & $13(68.4)$ \\
Born in New Zealand & $8(50.0)$ & $15(78.9)$ \\
Ethnic Group, New Zealand European & $7(43.8)$ & $15(78.9)$ \\
Ethnic Group, Māori & $1(6.3)$ & $0 \quad(0)$ \\
Other Ethnic Group, self-defined: Sri Lankan, & & \\
UK/Australian, Hungarian parents, Indian, European, & $8(50.0)$ & $4(21.1)$ \\
Anglo/Irish, Irish, Chinese, Mother of Māori child & & \\
\hline
\end{tabular}

Table 1. Demographic details of workshop participants $N=16$, control group $N=19$ (one participant did not provide demographic details)

\begin{tabular}{ccccc}
\hline & $\begin{array}{c}\text { Participants pre } \\
\text { seminar }\end{array}$ & $\begin{array}{c}\text { Participants post } \\
\text { seminar }\end{array}$ & $\begin{array}{c}\text { Control } \\
\text { first round }\end{array}$ & $\begin{array}{c}\text { Control second } \\
\text { round }\end{array}$ \\
\hline CULTURE & 17.7 & 18.1 & 19.3 & 17.9 \\
EMPOWER & 12.1 & 13.0 & 11.9 & 11.9 \\
EXPLAN & 16.2 & 16.5 & 15.8 & 15.9 \\
JUDGE & 16.7 & 16.6 & 15.8 & 16.2 \\
Total & 62.7 & 64.3 & 62.9 & 61.9 \\
\hline
\end{tabular}

Note: CULTURE - Cultural Self-Awareness domain, EXPLAN - Explanatory Model Elicitation domain, JUDGE - Non-judgemental domain, EMPOWER - Cultural Empowerment/Medical knowledge transmission skills Table 2. Mean questionnaire scores, domains and total from 16 workshop participants and 19 control group members

In both sets of co-variance calculations, there was an increase in total and domain scores for the workshop group as compared with the control group (Total score increase $p=.33$, with last observation carried forward $p$ $=.27$ ). However, this increase was not statistically significant.

The pre-intervention scores of the workshop and control groups (35 questionnaires) were also reviewed to see whether demographic factors affected cultural competency scores. Total scores did not differ significantly for gender $(t$-statistic $=0.6167, p=.5417)$, age (Pearson's coefficient correlation $r=.17, p=.3704$ ), or for whether a doctor was born in New Zealand ( $t$ statistic $=1.3190, p=.1963)$. There was however a significant difference for the total scores when prior cultural competency training was considered $(p=.03)$.

\section{B. CPD Evaluation Form}

CPD evaluation results were overwhelmingly positive both in terms of the workshop's content and its relevance to participants. Table 3 shows the results in full from 15 completed forms, ten from the first workshop (100\% of participants including one non-physician) and five from the second workshop (62.5\% of participants).

\begin{tabular}{|c|c|c|c|c|c|}
\hline & $\begin{array}{c}\text { Strongly } \\
\text { disagree (1) }\end{array}$ & $\begin{array}{l}\text { Disagree } \\
\text { (2) }\end{array}$ & $\begin{array}{l}\text { Agree } \\
\text { (3) }\end{array}$ & $\begin{array}{l}\text { Strongly } \\
\text { agree (4) }\end{array}$ & $\begin{array}{l}\text { Mean } \\
\pm \text { SD }\end{array}$ \\
\hline $\begin{array}{l}\text { Contained no commercial or professional bias in the educational } \\
\text { content }\end{array}$ & & & 6.7 & 93.3 & $3.9 \pm 0.25$ \\
\hline Presented new information & & 6.6 & 60 & 33.3 & $3.3 \pm 0.57$ \\
\hline Was appropriate for local conditions and requirements & & & 60 & 40 & $3.4 \pm 0.49$ \\
\hline $\begin{array}{l}\text { Was well administered in terms of course information, registration and } \\
\text { certification }\end{array}$ & & & 40 & 60 & $3.6 \pm 0.49$ \\
\hline Please comment on the suitability of the format of the delivery & & & 46.7 & 53.3 & $3.5 \pm 0.5$ \\
\hline Was it primary health care focused and driven & & & 46.7 & 53.3 & $3.5 \pm 0.5$ \\
\hline Provided a stimulating learning environment & & & 53.3 & 46.7 & $3.5 \pm 0.5$ \\
\hline Conveyed relevant information & & & 60 & 40 & $3.4 \pm 0.49$ \\
\hline Updated my knowledge in this area & & 6.6 & 60 & 33.3 & $3.3 \pm 0.57$ \\
\hline Gave ample opportunity for participant input, feedback and evaluation & & & 20 & 80 & $3.8 \pm 0.4$ \\
\hline Was well advertised with clearly stated course information & & & 60 & 40 & $3.4 \pm 0.49$ \\
\hline
\end{tabular}

Table 3. CPD evaluation form results (in \%), $N=15$

\section{Feedback}

All comments relating to the workshop as a whole were positive. It was described as "interesting and very helpful", "fun and enlightening", "fun and interesting". One participant, however, was uncomfortable with role play in which participants played genders and ethnicities different from their own. This led to a discussion during the workshop in which a second participant agreed that role players should maintain their own gender and ethnic identity. Other workshop participants felt that playing "different" roles was a beneficial part of role play, pertinent to cultural competency, and should be done. 


\section{Interviews}

Several themes were identified from the interviews some of which showed common ground between all the interviewees, others revealed conflicting views (Appendix B). Those that relate particularly to the acceptability of cultural competency are considered below. Whilst the interviewees have agreed to be identified in this article, their responses have been anonymised, and are identified as IP1 and IP2 (Pakeha) and IM1 and IM2 (Māori).

1) Equality and social justice: All the interviewees expressed similar ideas regarding the importance of equality and social justice in their work.

"We should work in a socially accountable way and that those who suffer the greatest disparities are those for whom the greatest health gains are available if we provide our skills for them."

"What can I do to help this person get a better deal?"

"It's not just about being humble about other people's cultures and being interested in them and having an enquiring mind and being patient-centred but it's more than that; It's actually about doing it for a reason to improve the inequalities that we've got."

2) Màori health education versus cultural competency education: There was unanimous support for teaching generalisable cultural competency. They were similarly in agreement that, in New Zealand, education on Māori is of key importance. There was, however, no consensus as to whether interventions on generalisable skills should continue to be combined with, and to a certain degree secondary to, education about Māori health issues.

IM1 argued that cultural competency education should be taught under the framework of Māori health education and feared that stand-alone education on generalisable skills could distract from the central need of addressing Māori health inequalities:

"If Māori is not explicit in your training or in any training around cultural competency, are we educating to maintain disparity?"

IM1 argued that skills learnt as part of education about Māori can be applied to other situations and that this removes the need for additional cultural competency education:

"I think if they can learn to work with Màori, at least they've got that skill under their belt and then some of those skills are going to be transferrable."

The other interviewees expressed some unease about the current practice in New Zealand of amalgamating cultural competency education with courses on Māori health. IP2 argued that they were two distinct and vital subjects that required separate educational approaches:

"I think there should be Mãori health training and then there should be cultural competency... The Màori health stuff needs to almost probably stand alone because it's a big factor and a big issue."

IM2 suggested that under the current situation, generalisable skills tended to be overshadowed by education on Māori health:

"When you say cultural competency, people automatically think that you're talking about engaging with Māori."

IP1 worried that it was currently difficult for educators to effectively teach generalisable skills when they were required to focus on Māori health issues. He believed that this requirement was particularly difficult for Māori educators.

"Some Māori who are teaching cultural competency are actually disabled from doing the culture general stuff very well because of the extent of their own agenda being needing to know about Māori culture."

IP1 and IP2 suggested that in present-day New Zealand, with its large number of ethnic groups, the current focus on only one or a limited number of ethnic groups may be inappropriate.

"I am concerned more about how we can improve things for the vast diversity of cultural backgrounds." 
"We are more diverse and it's that whole sense of diversity that we need to deal with and we need have some keys to being culturally competent for that."

\section{3) Difficulties for Māori and Pakeha health} professionals in discussing cultural competency education with each other: There was a consensus that interviews suggested that these issues are politically sensitive and that communication difficulties impede open discussion about cultural competency education. IM2 suggested the need to develop relationships between Māori and non-Māori doctors:

"So people feel safe enough to say what they're thinking."

IP1 argued that,

"All the issues around racism and colonisation... They are part of the difficulty in communicating... the power differential between the stereotypical white and stereotypical Māori is unbalanced."

IP2 also noted a sense of division between Māori and non-Māori doctors,

“There is a divide but I don't think it's deliberately set up but I think there a few protagonists who [would] perpetuate it if they possibly could."

\section{DISCUSSION}

This study considered the efficacy and acceptability of generalisable cultural competency to GPs in a New Zealand setting of familiarity with ethnically focused cultural education. The non-significant increase in selfassessment scores for the physicians attending the workshop suggests an improvement in their cultural competency. Feedback from participants showed that they considered the workshop to be acceptable and appropriate to their needs. However, interviews with medical educators revealed the complexities and potential difficulties of introducing generalisable cultural competency to curricula in which specific ethnic education exists.

This research is relevant to the particular situation in New Zealand but also to medical education worldwide where cultural competency training often continues to be ethnically or racially focused (Beach et al., 2005; Horvat,
Horey, Romios, \& Kis-Rigo, 2014). This study also contributes to the wider base of cultural competency research, a field where adequate evaluation of educational programmes and appropriate assessment tools are lacking (Dogra, \& Karnik, 2004; Jernigan, Hearod, Tran, Norris, \& Buchwald, 2016; Lie, Lee-Rey, Gomez, Bereknyei, \& Braddock, 2010). Furthermore, it participates in the discussion as to the place of medical education in improving ethnic minority and indigenous peoples' health and in reducing disparities between population groups (Brach \& Fraser, 2000; Durie, 2003).

A limitation of this study is the low number of GPs who chose to attend the workshop, which can be explained in part by its setting: the workshop being offered as part of non-compulsory CPD programming with many options. In addition, as "Cultural Competency" advisory standards appear in the Medical Council of New Zealand guidelines (MCNZ, 2016) and in The Royal New Zealand College of General Practitioners guidelines (RNZGP, 2007) it may be that their ubiquitous presence makes physicians feel that they do not need further instruction.

The study failed to show a significant increase in CCAT scores one month after the workshop. While this may be due to the small total number of participants it is also possible that those choosing to participate in cultural competency education already possess an interest in the subject and a higher degree of competency (Godkin \& Savageau, 2001) and thus, have less potential for improvement. The study did, however, reveal that the only demographic significantly linked to higher questionnaire scores was previous cultural competency training. The need for self-reflection, an element of the workshop, may have led participants to take a stronger critical stance when completing the second round of questionnaires, consequently producing lower scores (Chun, Jackson, Lin, \& Park, 2010). It is also possible that the mere act of completing the questionnaire contributed to increased self-awareness of the complexities of cultural competency. The slight decrease for the control group suggests this was not the case.

In this study, the acceptability of generalisable cultural competency was evident in the positive written and faceto-face feedback as well as in the CPD evaluation forms. However, the workshop participants were not asked to compare this teaching session with other ethnically focused cultural competency education that they may have experienced previously. Thus, while it is possible to conclude from their feedback that participants considered the workshop to be relevant and appropriate to their needs, it is not possible to conclude that they found it more appropriate or more relevant than 
ethnically focused education. Additionally, the presence of only one Māori participant may mean that the Māori perspective is under-represented in the feedback from the workshop although the diversity of participants' own ethnic backgrounds does reflect the make-up of New Zealand's current doctor workforce. Generalisable cultural competency's acceptability from a broader perspective of medical education in New Zealand cannot be concluded from this study, with the interviewees suggesting diverse possibilities for cultural competency education: from a standalone generalisable subject to Māori focused education.

The question of how generalisable cultural competency should fit into current educational curricula, and whether it should be taught as a standalone subject or within the rubric of education about minority groups, remains a complex and fraught one (Gray, 2007; Jones et al., 2010). Whilst a majority of medical educators propose cultural competency as a generalisable subject (Betancourt, 2006; Gregg \& Saha, 2006; Sorensen et al., 2017), the necessity of ethnic groups having their own specific cultural needs addressed in medical education is also supported (Eiser \& Ellis, 2007; Jones et al., 2010). In addition, in New Zealand, the Treaty of Waitangi makes an obligation towards Māori to right past injustices and by implication, reduce health discrepancies. Māori groups have become increasingly involved in education on Māori health and cultural competency in an attempt to meet these obligations (McPherson, Harwood, \& McNaughton, 2003).

It was apparent from the preparatory stages of this research when the seminar content was reviewed with colleagues, through to the seminars and the interviews that these are sensitive and potentially politically charged issues, not easily discussed. In particular, the interviewees suggested that open discussion about cultural issues, between educators from different ethnic backgrounds was difficult.

It may be that, in order to adequately address the acceptability of generalisable cultural competency in New Zealand, the apparent communication difficulties between Pakeha and Māori medical professionals also need to be tackled. Creating separate focus groups of Māori and non-Māori physicians could allow maximum freedom of expression with regards to cultural competency education. The issues raised could then form the basis of workshop content and mediation. The role of advocate medical professionals in promoting the needs of specific groups and creating an academic agenda is seen worldwide and is likely to be accompanied by similar difficulties to those found in New Zealand
(Australian Indigenous Doctors Association, n.d.; Marcy, 2011).

This study adds to the body of work in which cultural competency has been delivered in workshops (Carter et al., 2006; Genao, Bussey-Jones, St. George, \& CorbieSmith, 2009; Ho, Yao, Lee, Beach, \& Green, 2008; Khanna, Cheyney, \& Engle, 2009; Ross et al., 2010). Some of these studies were able to demonstrate improvements in participants' cultural competency following educational interventions (Carter et al., 2006; Genao et al., 2009; Ho et al., 2008) although measures of patients' health outcomes were unaffected (Khanna et al., 2009). This research also confirms that cultural competency education based on generalisable skills, rather than on specific ethnic or racial groups, can be effective (Khanna et al., 2009; Thom, Tirado, Woon, \& McBride, 2006; Webb \& Sergison, 2003).

Further research is now needed into how cultural competency interventions can best improve the skills and abilities of health care professionals in today's multicultural world. For instance, no attempt has been made to compare the acceptability or impact of specific and generalisable cultural competency interventions. There is also a need for further evaluation of how best to deliver generalisable cultural competency itself. Particularly, in the case of post-graduate physicians, there is a lack of research into the effectiveness of interventions. Further investigation is needed into the most effective way to improve the cultural competency of a large number of physicians who have never been exposed to the subject. A number of questions remain unanswered. Are short workshops as effective as long ones? Is attendance on a single occasion sufficient or is regular reinforcement required? Is the teaching of multi-disciplinary groups useful or is it preferable to teach professionals with their peers?

The dilemmas raised in this research, while specific to the situation in New Zealand, are likely to be echoed globally in medical education. These include the need to improve dialogue between advocates of ethnic minorities and educators and amongst physicians themselves, and the need to marry an acknowledgement of the needs of specific groups in society with the realisation that the cultural identity of doctors and patients is often highly complex, varied and multi-faceted. It is vital to dispel fears that generalisable education will decrease attention on health disparities suffered by specific ethnic and racial groups. It needs to be demonstrated that generalisable cultural competency can exist alongside, and supplement interventions relating to disadvantaged groups, rather than replace them. 
The authors suggest that cultural competency medical education be generalisable and integrated both vertically and horizontally through pre- and post-graduate medical studies, and in the case of New Zealand be separate and distinct from the subject of Māori health. We advocate that generalisable cultural skills training should be a distinct part of medical education and taught separately from courses regarding the health and culture of specific ethnic groups.

\section{CONCLUSION}

Notwithstanding the small number of participants, this study demonstrates the acceptability of a generalisable cultural competency workshop for participants already familiar with ethnically focused cultural education. Selfassessment scores suggest an increase in cultural competency for seminar participants. The study interviews confirm the acceptability of generalisable cultural competency as a subject but also illustrate the complexity of its potential insertion into medical curricula. It appears that while generalisable cultural competency is widely acceptable to both educators and learners its place in medical curricula is, like culture itself, a complex and disputed subject.

\section{Notes on Contributors}

The authors would like to emphasise that the views expressed in the submitted article are those of the authors alone and not an official position of their institutions. All contributors consented to be named.

KT designed and carried out the research. SS made substantial contributions to the conception and design of the study as well as to the drafting the manuscript. Both authors have given approval to this final version and are accountable to all aspects of the work.

\section{Ethical Approval}

Prior to the commencement of this study, research details were reviewed by the National Ethics Committee of the New Zealand Ministry of Health which responded that it was unnecessary to apply for formal ethical approval.

\section{Funding}

All authors declare no financial support from or relationship with any organisation which might have an interest in the submitted work.

\section{Declaration of Interest}

Authors declared that there was no conflict of interest involved in this paper.

\section{References}

Australian Indigenous Doctors Association. (n.d.). Cultural safety. Retrieved from https://www.aida.org.au/our-work/cultural-safety

Beach, M. C., Price, E. G., Gary, T. L., Robinson, K. A., Gozu, A., Palacio, A., ... Cooper, L. A. (2005). Cultural competence: A systematic review of health care provider educational interventions. Medical Care, 43(4), 356-373.

Betancourt, J. R. (2006). Cultural competence and medical education: Many names, many perspectives, one goal. Academic Medicine, 84(6), 499-501.

Brach, C., \& Fraser, I. (2000). Can cultural competency reduce ethnic and racial health disparities? A review and conceptual model. Medical Care Research and Review, 57(Suppl 1), 181-217.

Camplin-Welch, V. (2007). Cross-cultural resource for health practitioners working with culturally and linguistically diverse (CALD) clients. Wellington, New Zealand: Waitemata District Health Board and Refugees as Survivors New Zealand Trust.

Canty, A., \& Ripley, B. (2012). Boot: Bootstrap (S-Plus) Functions. R package version 1.3-4.

Carter, M. M., Lewis, E. L., Sbrocco, T., Tanenbaum, R., Oswald, J. C., Sykora, W., ... Hill, L. D. (2006). Cultural competency training for third year clerkship students: Effects of an interactive workshop on student attitudes. Journal of the National Medical Association, 98(11), 1772-1778.

Chun, M. B. J., Jackson, D. S., Lin, S. Y., \& Park, E. R. (2010). A comparison of surgery and family medicine residents' perceptions of cross-cultural care training. Hawai'i Medical Journal, 69(12), 289-293.

Dogra, N., \& Karnik, N. (2004). Teaching cultural diversity to medical students. Medical Teacher, 26(8), 677-680.

Durie, M. H. (2003). The health of indigenous peoples: Depends on genetics, politics, and socioeconomic factors. BMJ, 326(7388), 510-511.

Eiser, A. R., \& Ellis, G. (2007). Cultural competence and the African American experience with health care: The case for specific content in cross-cultural education. Academic Medicine, 82(2), 176-183.

Falissard, B. (2012). Various methods used in psychometry [PDF File]. Retrieved from http://cran.r-project.org/web/packages/psy/ psy.pdf

Genao, I., Bussey-Jones, J., St. George, D. M., \& Corbie-Smith, G. (2009). Empowering students with cultural competence knowledge: Randomized controlled trial of a cultural competence curriculum for medical students. Journal of the National Medical Association, 101(12), 1241-1246.

Godkin, M. A., \& Savageau, J. A. (2001). The effect of a global multiculturalism track on cultural competence of preclinical medical students. Family Medicine, 33(3), 178-186.

Gray, B. (2007). English language difficulties at general practices in Auckland, New Zealand. A major limitation to good practice. The New Zealand Medical Journal, 120(1264), 10-12.

Gregg, J., \& Saha, S. (2006) Losing culture on the way to competence: The use and misuse of culture in medical education. Academic Medicine, 81(6), 542-547.

Helman, C. (1984). Culture, health and illness. London, England: Butterworth-Heinemann. 
Ho, M. J., Yao, G., Lee, K. L., Beach, M. C., \& Green, A. R. (2008). Cross-cultural medical education: Can patient-centered cultural competency training be effective in non-Western countries? Medical Teacher, 30(7), 719-721.

Horky, S. (2009). Cross cultural health care - Case studies. Retrieved from https://support.mchtraining.net/national ccce/ index.html

Horvat, L., Horey, D., Romios, P., \& Kis-Rigo, J. (2014). Cultural competence education for health professionals. Cochrane Database of Systematic Reviews, 2014(5), CD009405. https://doi.org/10.1002/14651858.CD009405.pub2

Jernigan, V. B. B., Hearod, J. B., Tran, K., Norris, K. C., \& Buchwald, D. (2016). An examination of cultural competence training in US medical education guided by the tool for assessing cultural competence training. Journal of Health Disparities Research and Practice, 9(3), 150-167.

Jones, R., Pitama, S., Huria, T., Poole, P., McKimm, J., Pinnock, R., \& Reid, P. (2010). Medical education to improve Maori health. The New Zealand Medical Journal, 123(1316), 113-122.

Kai, J., Bridgewater, R., \& Spencer, J. (2001). 'Just think of TB and Asians, that's all I ever hear': Medical learners' views about training to work in ethnically diverse society. Medical Education, $35(3), 250-256$

Khanna, S. K., Cheyney, M., \& Engle, M. (2009). Cultural competency in health care: Evaluating the outcomes of a cultural competency training among health care professionals. Journal of the National Medical Association, 101(9), 886-892.

Kleinman, A., Eisenberg, L., \& Good, B. (1978). Culture illness and care: Clinical lessons from anthropologic and cross-cultural research. Annals of Internal Medicine, 88(2), 251-258.

Kutob, R. N., Senf, J. H., \& Harris, J. M. (2009). Teaching culturally effective diabetes care: Results of a randomized controlled trial. Family Medicine, 41(3), 167-174.

Lie, D. A., Lee-Rey, E., Gomez, A., Bereknyei, S., \& Braddock, C. H. (2010). Does cultural competency training of health professionals improve patient outcomes? A systemic review and proposed algorithm for future research. Journal of General Internal Medicine, 26(3), 317-325.

Marcy, J. (2011, November 3). Advocates: Don't scrap minority health training programmes. Kaiser Health News. Retrieved from https://khn.org
McPherson, K. M., Harwood, M., \& McNaughton, H. K. (2003) Ethnicity, equity and quality: Lessons from New Zealand. British Medical Journal, 327(7412), 443-444.

Medical Council of New Zealand. (2016). Good medical practice. Retrieved from

https://www.mcnz.org.nz/about-us/publications/good-medicalpractice/

Medical Council of New Zealand. (2017, June 9). Strengthening the cultural competence of our doctors [Media release]. Retrieved from https://www.menz.org.nz/news-and-publications/media-rele ases/strengthening-the-cultural-competence-of-our-doctors

Núñez, A. E. (2000). Transforming cultural competency into crosscultural efficacy in women's health education. Academic Medicine, 75(11), 1071-1080

Ross, P. T., Cené, C. W., Bussey-Jones, J., Brown, A. F., Blackman, D., Fernández, A., ... Lypson, M. L. (2010). A strategy for improving health disparities education in medicine. Journal of General Internal Medicine, 25(Suppl 2), 160-163.

Smith, K., \& Jansen, C. (2006). A report on cultural competency training provided for two PHOs. New Zealand Family Physician, $33(5), 310-312$

Sorensen, J., Norredam, M., Dogra, N., Essink-Bot, M. L., Suurmond, J., \& Krasnik, A. (2017). Enhancing cultural competence in medical education. International Journal of Medical Education, 8, 28-30

The Royal New Zealand College of General Practitioners. (2007). Cultural competence: Advice for GPs to create and maintain culturally competent practices. Retrieved from http://oldgp16.rnzcgp.org.nz/assets/documents/CORNERSTONE/ Cultural-Competence-Pullout-Sep-13.pdf

Thom, D. H., Tirado, M. D., Woon, T. L., \& McBride, M. R (2006). Development and evaluation of a cultural competency training curriculum. BMC Medical Education, 6, 38 .

Webb, E., \& Sergison, M. (2003). Evaluation of cultural competence and antiracism training in child health services. Archives of Disease in Childhood, 88(4), 291-294.

*Katharine Thomas

Department of Family Medicine,

Tel Aviv-Yafo and Dan Petach Tikva Districts Clalit, Health Services and Department of Family Medicine, Tel Aviv University,

Ramat Aviv PO Box 39040, Tel Aviv 6997801

Tel: 00972549293441

Email:marshykd@gmail.com 


\section{Thank you for taking the time to fill out this short cultural competency questionnaire}

It will help us learn about your views and practices in regards to treating patients from different cultural backgrounds. Your participation will assist in the development and evaluation of a new cultural competency course and is much appreciated. Results may also be published as part of research. If you do return the questionnaire, you are giving consent for use of the information, however it will be kept strictly confidential and any identifying material will be removed. If you have any questions, please contact Dr. Katy Thomas .email : marshykd@gmail.com

Please indicate your agreement with each of the following statements:

1. I understand the term "Culture"

2. I am able to describe my culture to a peer who is unfamiliar with me:

3. I am able to describe my own beliefs about health and illness to a person from a different background than mine.

4. Ethnic and cultural differences between my patients and me rarely get in the way of effective medical care.

5. I am very good at dealing with patients from different ethnic and cultural groups.

6. I am very sensitive to cultural differences between my patients and myself.

7. I find that I can communicate effectively with just about any kind of patient.

8. A good doctor can always get around any language barriers between him or her and the patient.

Strongly
Disagree

1

1

1

1

2

3

1

2

3

1

2

3

1

2

3

1

2

3
4

4

4

4

4

4

4

4 


\begin{tabular}{|c|c|c|c|c|}
\hline $\begin{array}{l}\text { Please indicate your agreement with each of the } \\
\text { following statements: }\end{array}$ & $\begin{array}{l}\text { Strongly } \\
\text { Disagree }\end{array}$ & Disagree & Agree & $\begin{array}{l}\text { Strongly } \\
\text { Agree }\end{array}$ \\
\hline $\begin{array}{l}\text { 9. Patients' lack of motivation to obtain knowledge is } \\
\text { the main reason for their non-adherence to medical } \\
\text { therapy. }\end{array}$ & 1 & 2 & 3 & 4 \\
\hline $\begin{array}{l}\text { 10. Most of my patients want me to tell them how to } \\
\text { manage their medical problems. }\end{array}$ & 1 & 2 & 3 & 4 \\
\hline \multicolumn{5}{|l|}{$\begin{array}{l}\text { 11. In dealing with a patient who is not following } \\
\text { diabetes recommendations, adherence can best be } \\
\text { achieved by... }\end{array}$} \\
\hline $\begin{array}{l}\text { a. Strongly stating the medical complications } \\
\text { of diabetes (e.g., blindness, amputation, etc.) }\end{array}$ & 1 & 2 & 3 & 4 \\
\hline $\begin{array}{l}\text { b. Explaining that insulin injections may be } \\
\text { necessary for those patients who are not } \\
\text { controlled on oral medications. }\end{array}$ & 1 & 2 & 3 & 4 \\
\hline
\end{tabular}

\begin{tabular}{|l|c|c|c|c|}
\hline $\begin{array}{l}\text { Please indicate your level of } \\
\text { comfort in performing the } \\
\text { following tasks with a patient } \\
\text { whose culture may be different } \\
\text { from your own }\end{array}$ & $\begin{array}{c}\text { Below Average } \\
\text { Comfort } \\
\text { Level }\end{array}$ & $\begin{array}{c}\text { Average } \\
\text { Comfort } \\
\text { Level }\end{array}$ & $\begin{array}{c}\text { Above Average } \\
\text { Comfort } \\
\text { Level }\end{array}$ & $\begin{array}{c}\text { Excellent } \\
\text { Comfort } \\
\text { Level }\end{array}$ \\
\hline $\begin{array}{l}\text { 12. Sharing your knowledge } \\
\text { about the pathophysiology of } \\
\text { illness. }\end{array}$ & 1 & 2 & 3 & 4 \\
$\begin{array}{l}\text { 13. Explaining the benefits of a } \\
\text { recommended treatment }\end{array}$ & 1 & 2 & 3 & 4 \\
$\begin{array}{l}\text { 14. Addressing patients' fears } \\
\text { regarding their illness or its } \\
\text { treatment }\end{array}$ & 1 & 2 & 3 & 4 \\
$\begin{array}{l}\text { 15. Addressing barriers to } \\
\text { adherence to therapy. }\end{array}$ \\
$\begin{array}{l}\text { 16. Empowering patients to take } \\
\text { an active role in their illness } \\
\text { treatment. }\end{array}$ & 1 & 2 & 3 & 4 \\
\hline
\end{tabular}


Please indicate how often you perform the following items in your practice

\section{Never}

Never

Rarely

Rarely

Ask patients about...

17. Their views as to the cause of their illness

1

18 Their views regarding their treatment

19. Their use of traditional remedies and herbal medications to treat their illness

20. Their economic situation and its influence on their illness and its treatment

21. Family/community support and its influence on their illness and treatment

1

1

1

1

12

2

3

2

3
2
3

3

4

4

34

$3 \quad 4$

Any Comments 
Please indicate the following:

Your name:

Your age:

Gender: $\quad$ F/M (circle one)

Name of the clinic where you currently practice:

Have you completed GP vocational training in New Zealand?

Yes/No (circle one)

Have you completed GP vocational training (or equivalent) in another country?

Yes/No (circle one)

Were you born in New Zealand?

Yes/No (circle one)

Which ethnic group do you belong to?

New Zealand European

Maori

Pacific Island

Chinese

Indian

Other, please state

Please estimate the total number of hours of training you have had in crosscultural medical issues: less than 1 hour 1-3 hours 4-6 hours 7-10 hours greater than 10 hours

Thank your for completing this questionnaire! 


\section{Cultural Competency Questionnaire Scoring System}

Total adapted CCAT Score $=$ Sum of all items with reverse coding for items in the non-judgemental subscale

Domain: Cultural Self-awareness

Items: $1,2,3,5,6,7$

Domain: Being Non-judgmental

Items: 4, 8, 9, 10, 11

Domain: Cultural Empowerment/Medical Knowledge Transmission Skills

Items: $12-16$

Domain: Explanatory Model Elicitation

Items: $17-21$ 


\section{Interview Core Topics and Questions}

Interviewee background: cultural and professional

Interviewee definition of cultural competency and its ideal goals

Interviewee thoughts about when cultural competency should be introduced and taught in the medical curriculum.

Undergraduate/postgraduate/GP

Cultural competency, "critical consciousness" health care disparities - are these interchangeable, is one preferable?

Role play in the seminar. Is it culturally inappropriate to take on different ethnic or gender identities?

Who should be teaching cultural competency in New Zealand, Māori or non-Māori?

Negative feelings from non-Māori that cultural competency has become an ethnically specific Māori dominated topic

Should the generalisable skills of cultural competency be taught in New Zealand?

Should cultural competency and Māori health exist as distinct topics for medical education?

Are there problems in New Zealand between Māori and non-Māori medical educators?

Should Māori and non-Māori health care professionals take part in different educational programmes?

\section{Themes}

*Equality and Social Justice

*Cultural competency vs Māori Health Education

*Desired Educational Outcomes

*Communication difficulties between Pakeha and Māori

*Māori vs Pakeha teachers- both per subject and per student

*Personal experiences

*Segregated education 